\title{
Омические контакты к приборным структурам на основе нитрида галлия
}

\author{
() А.В. Желаннов ${ }^{1}$, А.С. Ионов ${ }^{1}$, Б.И. Селезнев ${ }^{2}$, Д.Г. Федоров ${ }^{1}$ \\ ${ }^{1}$ АО „ОКБ-Планета“, \\ 173004 Великий Новгород, Россия \\ ${ }^{2}$ Новгородский государственный университет им. Ярослава Мудрого, \\ 173004 Великий Новгород, Россия \\ E-mail: ZhelannovAV@okbplaneta.ru
}

Поступила в Редакцию 23 июля 2019 г.

В окончательной редакции 3 сентября 2019 г.

Принята к публикации 5 ноября 2019 г.

\begin{abstract}
Представлены исследования характеристик омических контактов к эпитаксиальным и ионно-легированным слоям нитрида галлия на основе системы металлизации $\mathrm{Cr} / \mathrm{Pt} / \mathrm{Au}$. Показана возможность формирования низкоомных контактов без использования высокотемпературной обработки. Для гетероструктур на основе $\mathrm{AlGaN} / \mathrm{GaN}$ показано улучшение характеристик омических контактов $\mathrm{Ti} / \mathrm{Al} / \mathrm{Ni} / \mathrm{Au}$ при использовании ионной имплантации через маску двуокиси кремния.
\end{abstract}

Ключевые слова: гетероструктура, нитрид галлия, омический контакт, система металлизации, ионная имплантация, быстрый термический отжиг, удельное контактное сопротивление.

DOI: 10.21883/FTP.2020.03.49028.9224

\section{1. Введение}

Нитрид галлия (GaN) как материал для высокотемпературных, высоковольтных, высокочастотных и сильноточных приложений позволяет существенно расширить операционные возможности полупроводниковой техники. Уникальное сочетание физических свойств, включающее большую ширину запрещенной зоны, высокую дрейфовую скорость насыщения электронов, большие напряжения пробоя, высокую теплопроводность, высокую химическую и термическую стабильность, позволяет рассматривать $\mathrm{GaN}$ как наиболее перспективный материал для создания микроэлектронных приборов нового поколения. Именно с внедрением $\mathrm{GaN}$ в настоящее время связывается прорыв в СВЧ и сильноточной электронике.

Одним из важных этапов формирования приборных структур на нитриде галлия является создание омических контактов. Они должны удовлетворять ряду требований: низкое контактное сопротивление, хорошая адгезия металлов к полупроводнику, ровный край границы контакта, устойчивость к электромиграции, высокая термостабильность, сохранение морфологии при термообработке, хорошая воспроизводимость.

Описание различных методов формирования омических контактов к гетероструктурам на основе $\mathrm{GaN}$ представлено в работах [1,2]. Выделены две группы методов: сплавная и несплавная технология формирования омических контактов. В сплавной технологии формирование омических контактов происходит за счет высокотемпературной обработки с взаимодействием системы металлизации и слоя полупроводника. Как правило, в такой технологии используются многослойные системы металлизации на основе композиции $\mathrm{Ti} / \mathrm{Al} / \mathrm{Ni} / \mathrm{Au}$. Для получения низкоомных контактов на основе системы металлизации $\mathrm{Ti} / \mathrm{Al} / \mathrm{Ni} / \mathrm{Au}$ необходим подбор толщины отдельных слоев и температурно-временны́х режимов обработки [3].

В несплавной технологии отсутствует высокотемпературная обработка, а получение омических контактов обусловлено формированием локальных областей сильно легированного материала. Получение таких областей возможно за счет селективного эпитаксиального доращивания сильно легированного полупроводника [4] или ионного легирования подконтактных областей путем внедрения ионов кремния [5].

Технология селективной эпитаксии основана на локальном выращивании сильно легированного слой нитрида галлия через маску диэлектриков. После удаления маски, формируются омические контакты на основе $\mathrm{Cr} / \mathrm{Au}[6]$.

В качестве контактной металлизации в несплавных методах используют композицию $\mathrm{Cr} / \mathrm{Au}$. Для предотвращения миграции $\mathrm{Au}$ в полупроводник используют диффузионные барьеры, например $\mathrm{Pd}$, обеспечивающий термостабильность несплавных омических контактов до температур $350-400^{\circ} \mathrm{C}[7,8]$.

Цель данной работы - оценка несплавных омических контактов $\mathrm{Cr} / \mathrm{Pt} / \mathrm{Au}$ к эпитаксиальным структурам GaN и традиционных сплавных контактов $\mathrm{Ti} / \mathrm{Al} / \mathrm{Ni} / \mathrm{Au}$ к гетероструктурам $\mathrm{AlGaN} / \mathrm{GaN}$ с подконтактными ионнолегированными слоями.

\section{2. Методика эксперимента}

\section{1. Формирование контактов на основе $\mathrm{Cr} / \mathrm{Pt} / \mathrm{Au}$}

Для проведения экспериментальных работ использовались эпитаксиальные структуры нитрида галлия, 
выращенные на 2-дюймовых сапфировых подложках методом химического осаждения из газовой фазы с использованием металлорганических соединений. В рамках работы проведено сравнение параметров омических контактов, сформированных на эпитаксиальных и ионнолегированных слоях $\mathrm{GaN}$.

В образце A использовался эпитаксиальный слой нитрида галлия с концентрацией носителей заряда $4 \cdot 10^{18} \mathrm{~cm}^{-3}$. В образце Б слой $n^{+}-\mathrm{GaN}$ создавался с помощью ионного легирования. Для формирования $n^{+}$-слоя использовалась технология ионной имплантации $\mathrm{Si}^{+}$в $\mathrm{GaN}$ [9]. Внедрение примеси проводилось с энергией 50 кэВ и дозой $10^{15} \mathrm{~cm}^{-2}$. Для предотвращения эффекта каналирования пластины располагались под углом $7^{\circ}$ к нормали падающего луча. Для активации внедренной примеси использовался фотонный отжиг. Отжиг проводился при температуре $1250^{\circ} \mathrm{C}$ в течение 1 мин в атмосфере азота [10]. В качестве защитного покрытия перед проведением фотонного отжига на поверхность $\mathrm{GaN}$ осаждалась пленка двуокиси кремния $\left(\mathrm{SiO}_{2}\right)$. После активации концентрация носителей заряда в слое $n^{+}-\mathrm{GaN}$ составляла величину $2 \cdot 10^{19} \mathrm{~cm}^{-3}$.

В качестве металлизации омических контактов для рассматриваемых эпитаксиальных структур использовалась система на основе $\mathrm{Cr} / \mathrm{Pt} / \mathrm{Au}$. Контакты формировались электронно-лучевым напылением системы металлизации с помощью взрывной фотолитографии. Оценка качества омических контактов проводилась по величине удельного контактного сопротивления $\left(\rho_{c}\right)$, определяемого методом длинной линии [11].

\section{2. Формирование контактов на основе $\mathrm{Ti} / \mathrm{Al} / \mathrm{Ni} / \mathrm{Au}$}

Исследование характеристик омических контактов на основе системы металлизации $\mathrm{Ti} / \mathrm{Al} / \mathrm{Ni} / \mathrm{Au}$ проводилось на гетероэпитаксиальных структурах, представленных на рис. 1.

Гетероэпитаксиальные структуры выращивались методом химического осаждения из газовой фазы с использованием металлорганических соединений на 2-дюймовых сапфировых подложках.

При использовании ионной имплантации необходимо сформировать локальные области сильно легированного материала. При этом необходимо, чтобы максимум распределения примеси приходился на уровень двумерного электронного газа, формируемого на границе раздела $\mathrm{AlGaN}$ и $\mathrm{GaN}$, т.е. на глубину $\sim 25$ нм. Проведенные ранее работы [10] показывают, что при заданных режимах легирования максимум распределения примеси приходится на глубину $\sim 100$ нм. Для решения данной проблемы, процесс имплантации проводился через диэлектрические пленки диоксида кремния толщиной 50 и 100 нм, служащие маской при проведении процесса легирования. Выбор толщины маски определялся расчетом средней проецированной длины пробега в системе $\mathrm{AlGaN}$, выполненным в программе расчета SRIM [12].

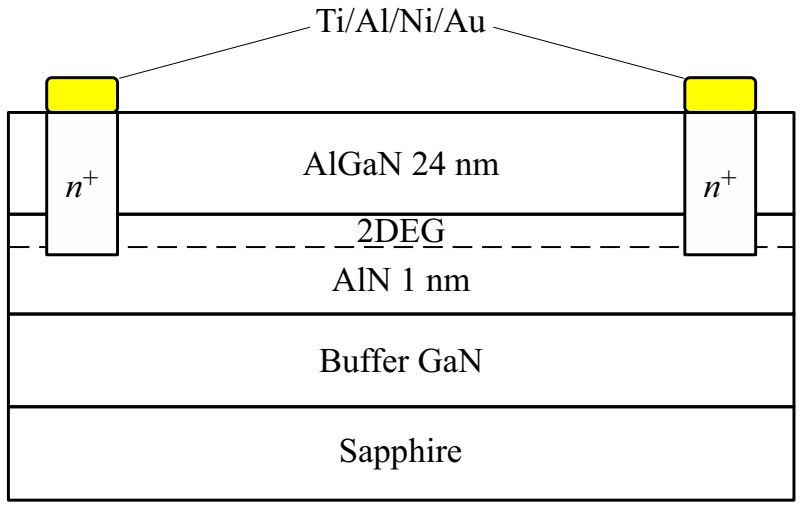

Рис. 1. Исходная структура $\mathrm{AlGaN} / \mathrm{GaN}$ с сформированными контактами $\mathrm{Ti} / \mathrm{Al} / \mathrm{Ni} / \mathrm{Au}$.

Для сравнения характеристик, имплантация проводилась и в образцы без маски.

После формирования областей сильно легированного материала создавалась система омических контактов к легированным областям. В качестве металлизации омических контактов использовалась система Ti/ $\mathrm{Al} / \mathrm{Ni} / \mathrm{Au}$. Для сравнения характеристик контакты создавались также к полупроводнику без процесса ионной имплантации. Контакты формировались электронно-лучевым напылением с использованием операции взрывной фотолитографии. После создания контактных площадок проводился отжиг металлизации при температуре $800^{\circ} \mathrm{C}$ в течение $30 \mathrm{c}$.

Измерение сопротивления контактов проводилось с использованием тестовых элементов на полуавтоматической станции Cascade Microtech. В качестве измерительной части для контроля параметров на постоянном токе использовался измеритель характеристик полупроводниковых приборов Agilent B1505A.

\section{3. Результаты измерений характеристик структур}

\section{1. Исследование характеристик контактов на основе $\mathrm{Cr} / \mathrm{Pt} / \mathrm{Au}$}

После напыления контакты показывали омические характеристики с сопротивлением $2.8 \cdot 10^{-6}$ и $9.1 \cdot 10^{-7}$ Ом $\cdot \mathrm{cm}^{2}$ для образцов с эпитаксиальным и ионно-легированным слоем $n^{+}-\mathrm{GaN}$ соответственно. Для оценки параметров контактов было проведено исследование влияния отжига на характеристики контактов. Отжиг проводился в диапазоне температур от 400 до $800^{\circ} \mathrm{C}$ в течение 1 мин.

Влияние отжига на величину удельного контактного сопротивления и среднеквадратичную шероховатость (rms) представлено на рис. 2,3 и в табл. 1.

Полученные контакты показывают омические характеристики вплоть до температур отжига $600^{\circ} \mathrm{C}$, при этом 
Таблица 1. Влияние температуры отжига на удельное контактное сопротивление $\left(\rho_{c}\right.$, Ом $\left.\cdot \mathrm{cm}^{2}\right)$

\begin{tabular}{l|c|c|c|c|c|c}
\hline & Без отжига & $400^{\circ} \mathrm{C}$ & $500^{\circ} \mathrm{C}$ & $600^{\circ} \mathrm{C}$ & $700^{\circ} \mathrm{C}$ & $800^{\circ} \mathrm{C}$ \\
\hline Эпитаксиальный слой $n^{+}-\mathrm{GaN}$ & $2.8 \cdot 10^{-6}$ & $2.2 \cdot 10^{-6}$ & $2.7 \cdot 10^{-6}$ & $6.9 \cdot 10^{-6}$ & Не омические & Не омические \\
Ионно-легированный слой $n^{+}-\mathrm{GaN}$ & $3.5 \cdot 10^{-7}$ & $1.1 \cdot 10^{-6}$ & $1.6 \cdot 10^{-6}$ & $6.8 \cdot 10^{-7}$ & $7.8 \cdot 10^{-5}$ & $5.9 \cdot 10^{-6}$
\end{tabular}

Таблица 2. Результаты расчета удельного контактного сопротивления контактов, изготовленных различными методами

\begin{tabular}{l|c|c}
\hline & Омический контакт & $\rho_{c}$, Ом $^{2} \mathrm{~cm}^{2}$ \\
\hline Без модификации & $\mathrm{Ti} / \mathrm{Al} / \mathrm{Ni} / \mathrm{Au}$ & $7.3 \cdot 10^{-6}$ \\
Ионная имплантация непосредственно в полупроводник & $\mathrm{Ti} / \mathrm{Al} / \mathrm{Ni} / \mathrm{Au}$ & $6.8 \cdot 10^{-6}$ \\
Ионная имплантация через маску $\mathrm{SiO}_{2}$ толщиной $50 \mathrm{Hм}$ & $\mathrm{Ti} / \mathrm{Al} / \mathrm{Ni} / \mathrm{Au}$ & $2.6 \cdot 10^{-7}$ \\
Ионная имплантация через маску $\mathrm{SiO}_{2}$ толщиной $100 \mathrm{Hм}$ & $\mathrm{T} / \mathrm{Al} / \mathrm{Ni} / \mathrm{Au}$ & $7.4 \cdot 10^{-6}$
\end{tabular}

сравнительно слабо изменяется удельное контактное сопротивление. Контакты становятся выпрямляющими при температурах отжига от $700^{\circ} \mathrm{C}$. Ухудшение характеристик вызвано процессами диффузии металлов в полупроводник при высокотемпературной обработке. Как показано на рис. 3, происходит резкое ухудшение морфологии поверхности, определяемой по величине среднеквадратичной шероховатости поверхности.

\section{2. Исследование характеристик контактов на основе $\mathrm{Ti} / \mathrm{Al} / \mathrm{Ni} / \mathrm{Au}$}

Формирование омических контактов к гетероструктурам $\mathrm{AlGaN} / \mathrm{GaN}$, как ранее отмечалось, проводилось на основе системы Ti/Al/Ni/Au с использованием ионного

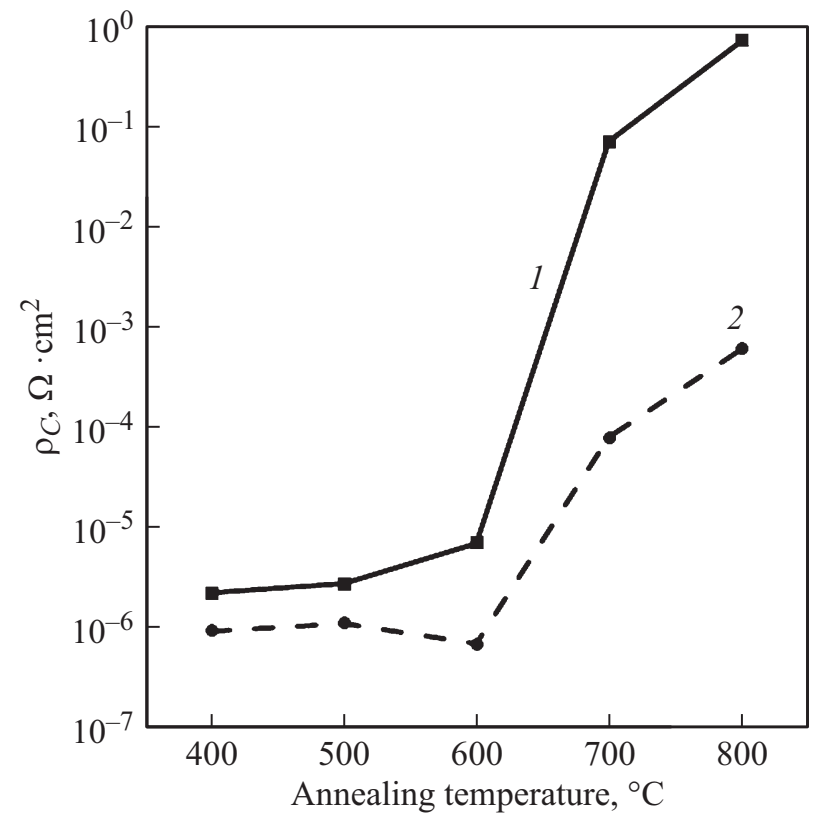

Рис. 2. Влияние термообработки на величину удельного контактного сопротивления контактов $\mathrm{Cr} / \mathrm{Pt} / \mathrm{Au}$ для эпитаксиального (1) и ионно-легированного (2) слоя $\mathrm{GaN}$. легирования поверхности с целью улучшения параметров омических контактов.

По описанной выше технологии были получены образцы с ионной имплантацией без диэлектрической пленки, через пленки $\mathrm{SiO}_{2}$ с толщинами 50 и 100 нм и без имплантации. Расчет величины удельного контактного сопротивления для разных образцов представлен в табл. 2.

В результате проведенных исследований установлено, что введение операции ионной имплантации через маску $\mathrm{SiO}_{2}$ толщиной 50 нм позволяет снизить величину удельного контактного сопротивления омических контактов.

На исследованных образцах были сформированы транзисторные структуры. Затворная металлизация была сформирована с помощью электронной литографии с

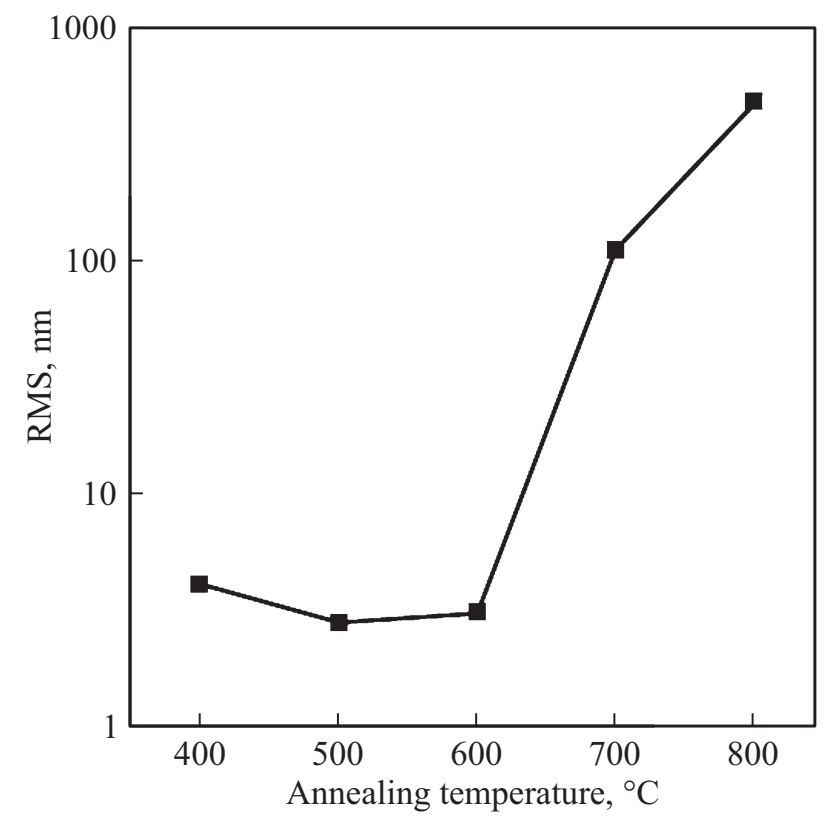

Рис. 3. Влияние термообработки на величину характеристики среднеквадратичной шероховатости контактов $\mathrm{Cr} / \mathrm{Pt} / \mathrm{Au}$. 

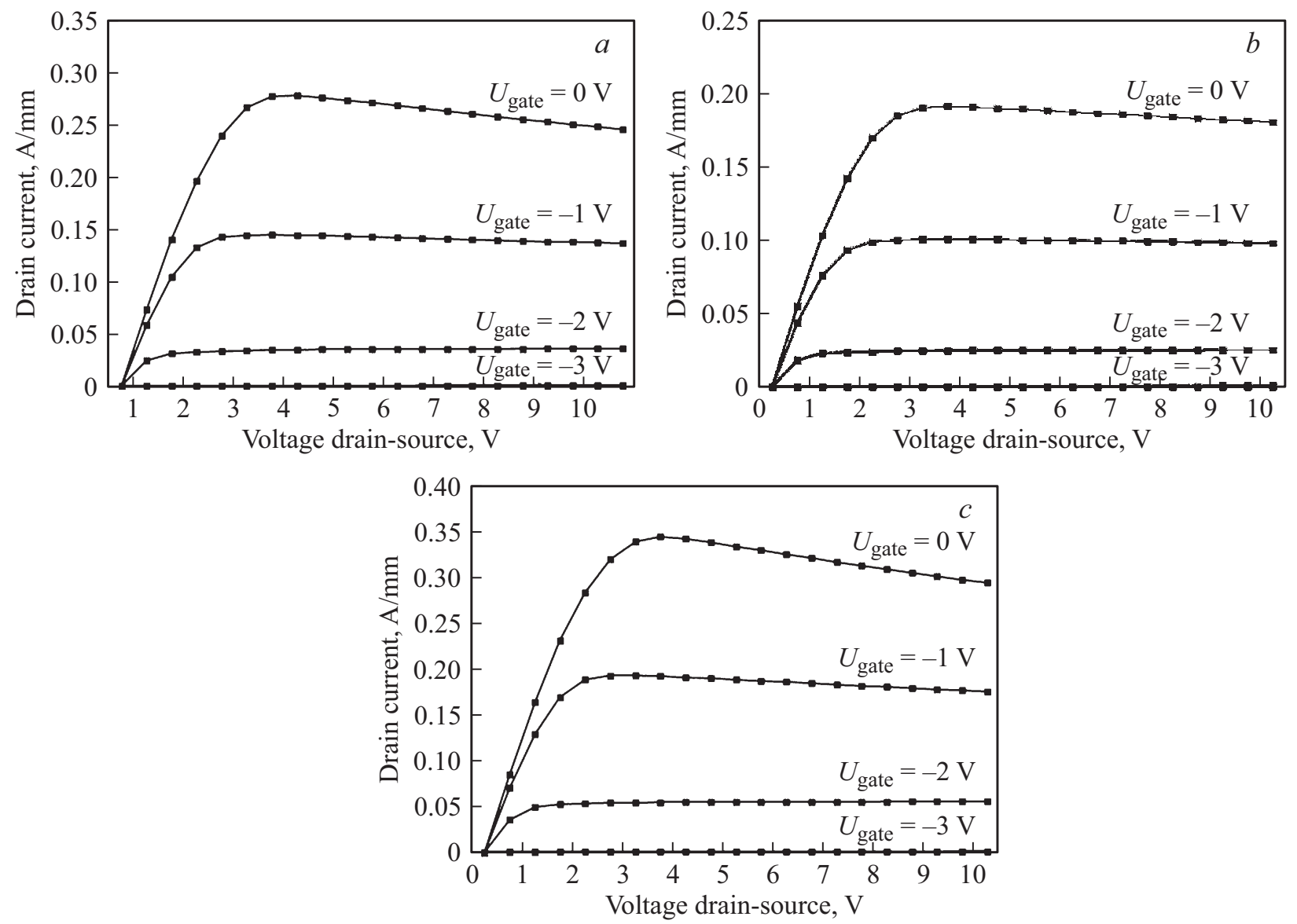

Рис. 4. Выходные вольт-амперные характеристики транзисторов с ионным легированием подконтактных областей: $a-$ ионная имплантация непосредственно в полупроводник, $b-$ ионная имплантация через маску $\mathrm{SiO}_{2}$ толщиной 100 нм, $c-$ ионная имплантация через маску $\mathrm{SiO}_{2}$ толщиной 50 нм.

последующим напылением системы металлизации на основе $\mathrm{Ni} / \mathrm{Au}$. После пассивации и формирования контактных площадок, были измерены статические выходные характеристики транзисторных структур, показанные на рис. 4.

На рис. 4 представлены выходные характеристики транзисторов на основе гетероструктур $\mathrm{AlGaN} / \mathrm{GaN}$ с использованием ионной имплантации как метода улучшения параметров омических контактов. Как видно из графиков, значения тока стока насыщения $I_{D}$ для структур с ионной имплантацией через маску $\mathrm{SiO}_{2}$ толщиной 50 нм оказались выше, чем для остальных структур.

\section{4. Заключение}

Исследована система металлизации $\mathrm{Cr} / \mathrm{Pt} / \mathrm{Au}$ для формирования омических контактов к эпитаксиальным и ионно-легированным слоям нитрида галлия. Показано, что использование данной системы позволяет получать омические контакты к $\mathrm{GaN}$ без применения высокотемпературного отжига. Данная система позволяет получить контакты с удельным контактным сопротивлением $\sim 2.8 \cdot 10^{-6} \mathrm{OM} \cdot \mathrm{cm}^{2}$ для эпитаксиального $n^{+}-\mathrm{GaN}$ слоя и $9.1 \cdot 10^{-7} \mathrm{OM} \cdot \mathrm{cm}^{2}$ для ионно-легированного $n^{+}-\mathrm{GaN}$ слоя.

Рассмотрена технология ионной имплантации через диэлектрическую маску, позволяющую уменьшать величину удельного контактного сопротивления и улучшать характеристики приборных структур. Показано улучшение параметров омических контактов с системой металлизации $\mathrm{Ti} / \mathrm{Al} / \mathrm{Ni} / \mathrm{Au}$ и выходных характеристик транзисторов на основе гетероструктур AlGaN/GaN при проведении ионной имплантации через маску $\mathrm{SiO}_{2}$ толщиной 50 нм.

\section{Финансирование работы}

Публикация подготовлена при финансовой поддержке Министерства образования и науки России в рамках проектной части государственного задания, проект № 3.3572.2017/ПЧ.

\section{Конфликт интересов}

Авторы заявляют, что у них нет конфликта интересов. 


\title{
Список литературы
}

[1] Д.Н. Слаповский, А.Ю. Павлов, В.Ю. Павлов, А.В. Клековкин. ФТП, 51 (4), 461 (2017).

[2] В.Ю. Павлов, А.Ю. Павлов. Нано- и микросистемная техника, 18 (10), 635 (2016).

[3] Z-S. Kim, H. Ahn. J. Korean Phys. Soc., 66 (5), 779 (2015).

[4] Z. Zheng, H. Seo, L. Pang. Phys. Status Solidi A, 208 (4), 951 (2011).

[5] F. Recht, L. McCarthy, S. Rajan, A. Chakraborty, C. Poblenz, A. Corrion, J.S. Speck, U.K. Mishra. IEEE Electron. Dev. Lett., 27 (4), 205 (2006).

[6] С.С. Арутюнян, А.Ю. Павлов, В.Ю. Павлов, К.Н. Томош, Ю.В. Федоров. ФТП, 50 (8), 1138 (2016).

[7] C. Zeng, S.M. Zhang, H. Wang, J.P. Liu, H.B. Wang, Z.C. Li, M.X. Feng, D.G. Zhao, Z.S. Liu, D.S. Jiang, H.Yang. Chin. Phys. Lett., 2 (1), 017301 (2012).

[8] M.L. Lee, J.K. Sheu, C.C. Hu. Appl. Phys. Lett., 91 (18), 182106 (2007).

[9] Б.И. Селезнев, Г.Я. Москалев, Д.Г. Федоров. ФТП, 50 (6), 848 (2016).

[10] А.В. Желаннов, Д.Г Федоров, Б.И.Селезнев. Вестн. Новг. гос. ун-та. Сер.: Техн. науки, № 6 (104), 24 (2017).

[11] G.K. Reeves. IEEE Electron. Dev. Lett., EDL-3 (5), 111 (1982).

[12] http://www.srim.org (дата обращения: 08.07.2019).

Редактор Г.А. Оганесян

\section{Ohmic contacts to gallium nitride based structures}

\author{
A.V. Zhelannov ${ }^{1}$, A.S. Ionov ${ }^{1}$, B.I. Seleznev ${ }^{2}$, \\ D.G. Fedorov ${ }^{1}$ \\ 1 JSC „OCB-Planet“, \\ 173004 Veliky Novgorod, Russia \\ 2 Yaroslav-the-Wise Novgorod State University, \\ 173004 Veliky Novgorod, Russia
}

\begin{abstract}
Studies of the characteristics of ohmic contacts to epitaxial and ion-doped gallium nitride layers based on the $\mathrm{Cr} / \mathrm{Pt} / \mathrm{Au}$ metallization system are presented. The possibility of forming lowresistance contacts without the use of high-temperature treatment is shown. For $\mathrm{AlGaN} / \mathrm{GaN}$-based heterostructures, an improvement in the characteristics of $\mathrm{Ti} / \mathrm{Al} / \mathrm{Ni} / \mathrm{Au}$ ohmic contacts using ion implantation through a silicon dioxide has been shown.
\end{abstract}

